\title{
A study to assess the respiratory impairments among the male beedi workers in unorganized sectors
}

\begin{abstract}
Aims: The dust of tobacco enters the respiratory system of beedi workers through inhalation during beedi-making and causes respiratory impairments. The aim of the present study is to evaluate the pulmonary functional status of male beedi workers and to detect the pulmonary function impairments among these workers. Materials and Methods: A standard questionnaire was followed to note the symptoms like cough, breathlessness, morning cough and chest tightness. The tendu leaves contain fungal spores in different phases of its processing, particularly when they were kept in bundles in moist condition before wrapping the beedi. In the present study, pulmonary function status assessment was done by spirometric method using Spirovit-SP-10 and Wright's peak flow meter. Out of the total subjects studied $(n=107)$, 56 were control subjects and 51 were workers exposed to beedi. Statistical Analysis: Paired t-test was done to determine the significant difference between beedi workers and control subjects. Result: A few workers reported symptoms of cough, breathlessness, morning cough and chest tightness. The respiratory symptoms were found higher in exposed beedi workers compared to control subjects. A trend of decrement of lung volumes with the increment of age and duration of work exposure was observed. The pulmonary function abnormalities found among the male beedi workers were obstructive, restrictive and 'combined restrictive and obstructive' type. Conclusion: The respirtory impairments among the beedi workers might be due to their exposure to the work environment.
\end{abstract}

Key words: Combined restrictive and obstructive type of impairments, obstructive, respiratory impairments, restrictive, tobacco dusts

\section{INTRODUCTION}

The respiratory impairments among the exposed workers were reported to be caused by the varieties of dusts in small and large scale industries generated during their production processes. ${ }^{[1]}$ The nature of respiratory diseases caused by

occupational dust is influenced by the type of dust and duration of exposure ${ }^{[2]}$ Occupational diseases are caused by a pathologic response of the patients to their working environment. ${ }^{[3]}$ In beedi workers, the occupational stress associated with long hours of work, exposure to tobacco dusts and poor working conditions are superimposed on the handicaps of poor socioeconomic and nutritional status. The salient features were that the subjects experienced symptoms like nausea, giddiness, vomiting, headache, tiredness, loss of appetite, weakness, cough and breathlessness. In response to the questionnaire, the problems reported by beedi workers were i) aches and body pain due to continuous work in a static posture $;$ ii) cough, which may be related to their exposure to tobacco dust; iii) stomach-related pains such as cramps, gas and spasmodic pains leading to diarrhea; iv) morning cough v) cough throughout the day; vi) chest tightness, etc.

Beedi-making is a skilled job. Beedis are made from processed tobacco wrapped in tendu leaves. The leaves are moistened by soaking them in water overnight. The wet leaves are then cut into pieces roughly rectangular in shape, in sizes depending on the length of the beedi. The processed tobacco in powdered form is thoroughly mixed by hand and then rolled on a piece of tendu leaf. A thread is then tied around it towards the narrower end to maintain the shape of a beedi. Nowadays the bundles of beedi are prepared with different numbers of beedis in a
B. P. Chattopadhyay, S. Kundu,

A. Mahata, S. K. Jane Alam Regional Occupational Health Centre (E), Indian Council of Medical Research, Salt Lake City, Kolkata, India

For correspondence: B. P. Chattopadhyay, Regional Occupational Health Centre (E), Indian Council of Medical Research, Block-DP, Sec-V, Salt Lake City,

Kolkata - 700 091, India.

E-mail:

bpc_rohc_icmr@yahoo.com

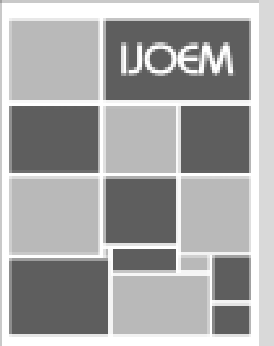


plastic pack. Earlier a bundle was formed with 24 beedis and wrapped with printed paper with the brand name and company's address on it. These bundles are packed together to make a bigger bundle according to necessity of the company. The bundles are then supplied to contractors.

In occupational respiratory diseases, spirometry is one of the most important diagnostic tools. It is the most widely used instrument to evaluate the pulmonary function status of a subject and can measure and judge the restriction or obstruction if any to lung function. ${ }^{[4]}$

The study results will help to evaluate the respiratory functional status of the male beediworkers exposed to tobacco dust during their work and to make them aware of methods to control the health hazards due to beedi-making as well as to implement preventive measures with regards to exposure and the consequent occurrence of respiratory impairments.

\section{MATERIALS AND METHODS}

The male beedi workers were considered as the subjects of this study. The selection of workers was made on a random basis by stratification. The study was carried out at Aurangabad, district Murshidabad, West Bengal, India. Out of the total subjects studied ( $\mathrm{n}=107), 56$ were control subjects and 51 were workers exposed to beedi. The control subjects were selected from those in the population who were not directly engaged in beedi-making but were associated with other jobs in the same area of study. The smoking history was taken and the frequency of smoking per day was noted using a questionnaire. Among the workers, those who smoked at least 5-6 beedis/cigarettes per day were included in the smoking category, those who had not smoked throughout their life were considered nonsmokers and those who had left smoking were considered ex-smokers. There were very few ex-smokers; so they were combined with the smoking category and analyzed. The personal histories of the individuals were also noted, giving special attention to respiratory impairments. Duration of work with their past and present work history was also recorded.

\section{Pulmonary function tests}

Vital capacity and forced vital capacity (FVC) were recorded using Spirovit-SP10 (Schillar Health Care Pvt. Ltd.,
Switzerland) and peak expiratory flow rate was recorded by Wright's peak flow meter (Clement and Clark, UK). Forced expiratory volume in one second $\left(\mathrm{FEV}_{1}\right)$ and the forced expiratory volume in one second as a percentage of FVC $\left(\mathrm{FEV}_{1 \%}\right)$, forced expiratory flow rates at 200-1200 ml, 25-75 and $75-85 \%$ were calculated from the same tracing. Before the recordings were taken, all subjects were well motivated, thus ensuring recording at optimum levels. ${ }^{[5]}$ The PFT measurements were made in a comfortable standing position. Body height and body weight were measured from a standard scale without footwear. All measured lung volumes obtained were expressed in terms of body temperature pressure saturated with water vapor. ${ }^{[6]}$ Body surface area was calculated using Du-Bois and Du-Bois formula. ${ }^{[7]}$ Pulmonary function test values were predicted from the standard prediction equation of Kolkata normal subjects. ${ }^{[8]}$ The criteria followed for categorization of the severity of restrictive impairments were based upon the ratios between predicted and observed values and the criteria for categorization of the severity of obstructive impairments were based upon $\mathrm{FEV}_{1 \%}{ }^{\left[{ }^{[5]}\right.}$

\section{Statistical analysis}

Students paired ' $t$ 'test was performed to determine whether there was any significant difference between the exposed and control workers.

\section{RESULTS}

All subjects (males, $\mathrm{n}=107$ ) were divided into two categories: control subjects (56) and exposed beedi workers (51). The physical parameters of control and exposed male beedi workers are presented in Table 1. The age, height, weight and body surface area of the control and exposed groups are comparable no significant differences were noticed. The lung volumes (SVC, FVC, $\left.\mathrm{FEV}_{1}, \mathrm{FEV}_{1 \%}\right)$ and flow rates $\left(\mathrm{FEF}_{200-1200 \mathrm{ml}^{\prime}}\right.$ $\mathrm{FEF}_{25-75 \%}, \mathrm{FEF}_{75-85 \%}, \mathrm{PEFR}$ ) of the control and exposed male beedi workers are presented in Table 2. It was found that the mean values of the lung volumes and flow rates of control subjects were higher than the exposed workers. Only the PEFR showed significantly higher values in control subjects compared to the exposed workers.

The different lung volumes and flow rates of both control and exposed male beedi workers according to the duration of exposure are presented in Figures 1 and 2 respectively. The

Table 1: Anthropometric and physical parameters of exposed and control male beedi workers (mean \pm SD)

\begin{tabular}{|c|c|c|c|c|}
\hline Parameters & $\begin{array}{c}\text { Beedi workers }(n=51) \\
\quad(\text { mean } \pm S D)\end{array}$ & $\begin{array}{c}\text { Control subjects }(n=56) \\
(\text { mean } \pm \text { SD })\end{array}$ & Percentage changes & $\boldsymbol{P}$ values \\
\hline Age (years) & $33.63 \pm 11.36$ & $35.34 \pm 12.71$ & -4.83 & NS \\
\hline Height $(\mathrm{cm})$ & $161.88 \pm 5.58$ & $160.50 \pm 5.73$ & +0.86 & NS \\
\hline Weight (kg) & $50.06 \pm 7.72$ & $52.21 \pm 8.71$ & -4.12 & NS \\
\hline $\mathrm{BSA}\left(\mathrm{m}^{2}\right)$ & $1.51 \pm 0.12$ & $1.53 \pm 0.12$ & -1.32 & NS \\
\hline $\mathrm{BMI}$ & $19.08 \pm 2.53$ & $19.84 \pm 3.07$ & -3.83 & NS \\
\hline
\end{tabular}

BSA $=$ Body surface area, BMI $=$ Body mass index, NS $=$ Nonsignificant 
Table 2: Lung volumes and flow rates of exposed and control male beedi workers (mean \pm SD)

\begin{tabular}{|c|c|c|c|c|}
\hline Parameters & $\begin{array}{l}\text { Beedi workers }(n=51) \\
\quad(\text { mean } \pm S D)\end{array}$ & $\begin{array}{c}\text { Control subjects }(n=56) \\
(\text { mean } \pm S D)\end{array}$ & Percentage changes & $P$ values \\
\hline SVC (I) & $3.86 \pm 0.70$ & $3.96 \pm 0.78$ & -2.52 & NS \\
\hline FVC (I) & $3.87 \pm 0.85$ & $3.96 \pm 0.66$ & -2.27 & NS \\
\hline $\mathrm{FEV}_{1}$ (I) & $3.46 \pm 0.84$ & $3.57 \pm 0.62$ & -3.08 & NS \\
\hline $\mathrm{FEV}_{1 \%}$ & $87.54 \pm 10.43$ & $89.79 \pm 5.11$ & -2.51 & NS \\
\hline $\mathrm{FEF}_{0.2-1.21 \mathrm{~m}(\mathrm{l} / \mathrm{Sec})}$ & $7.03 \pm 2.22$ & $7.25 \pm 1.70$ & -3.03 & NS \\
\hline $\mathrm{FEF}_{25-75 \%(/ / \mathrm{sec})}$ & $4.27 \pm 1.80$ & $4.66 \pm 1.30$ & -8.37 & NS \\
\hline $\mathrm{FEF}_{75-85 \%(\mathrm{VSec})}^{25 / 7 \%(\mathrm{Sec})}$ & $2.03 \pm 1.59$ & $1.82 \pm 0.68$ & +11.54 & NS \\
\hline PEFR (l/ $/ / \mathrm{min})$ & $469.61 \pm 94.05$ & $507.86 \pm 69.39$ & -7.53 & $<0.05$ \\
\hline
\end{tabular}

(NS $=$ Nonsignificant)

duration of exposure was categorically divided into three groups: up to 10 years, 11-20 years and above 20 years. A trend of gradual decrement of lung volumes was found in exposed subjects as the duration of exposure increased. A gradual decrement of lung volumes was noticed as the duration of exposure increased. In flow rates, only the $\mathrm{FEF}_{200-1200 \mathrm{ml}}$ showed gradual decrement with respect to duration of exposure ${ }_{i}$ but for $\mathrm{FEF}_{25-75 \%}$ and $\mathrm{FEF}_{75-85 \%}$, the highest level of exposed group the values are little a higher compared to the other two groups of workers having lesser working history.

Lung volumes and flow rates of both control and exposed subjects according to smoking habits are presented in Table 3. It is has been found that the smokers have lower pulmonary

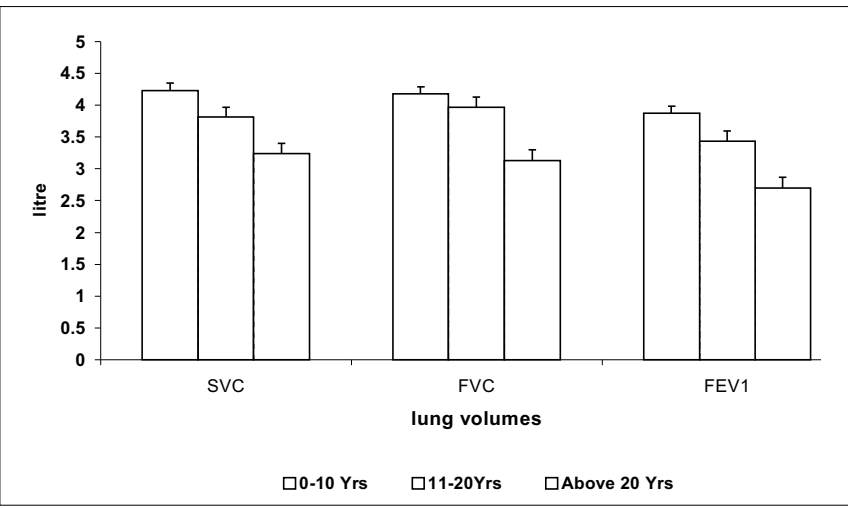

Figure 1: Comparison of lung volumes of male beedi workers according to duration of exposure

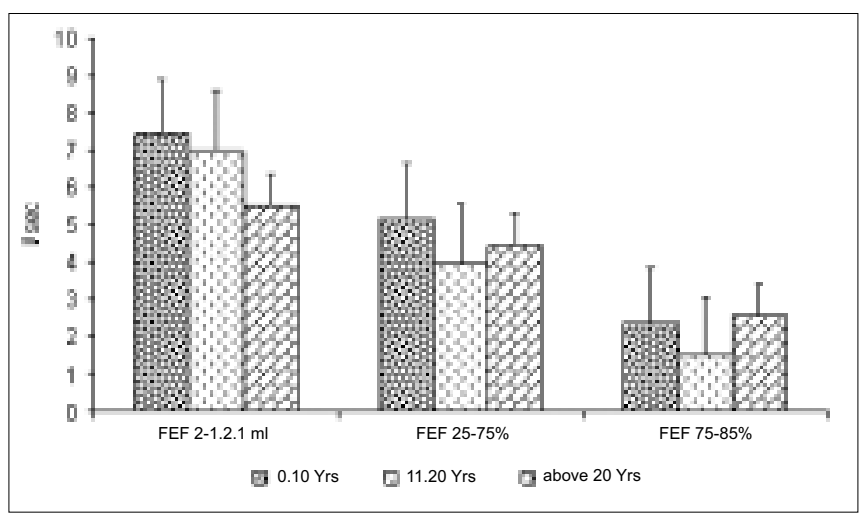

Figure 2: Comparison of flow rates of beedi workers according to duration of exposure function values compared to the nonsmokers. The mean PFT values of the control nonsmokers and smoker subjects are found higher compared to the exposed nonsmokers and smoker subjects. Among the comparisons, $\mathrm{FEV}_{1 \%}$ and PEFR between smoker controls and exposed showed significant differences. FVC, $\mathrm{FEV}_{1}$ in lung volumes of nonsmoker exposed subjects and in flow rates. $\mathrm{FEF}_{75-85 \%}$ in exposed nonsmoker and smoker subjects was found to be little higher compared to the control subjects of respective categories.

The respiratory symptoms as reported by the control and exposed subjects are presented in Figure 3. The respiratory symptoms like cough with breathlessness, morning coughs, cough throughout the day, chest tightness are reported. The percentage figures of these symptoms are significantly higher in exposed subjects compared to the control. Cough with breathlessness was found to be higher among all the symptoms in exposed as well as control subjects.

The spirometric assessment of the respiratory function impairments among the exposed workers and control subjects are presented in Figure 4. The respiratory impairments of restrictive, obstructive and 'combined restrictive and obstructive' type among the exposed workers as a whole are much higher (23.53\%) compared to control (3.56\%). According to category, in exposed workers, the restrictive type of impairment is $5.88 \%$, obstructive type is $11.76 \%$ and combined type is $5.88 \%$; the corresponding figures in control subjects

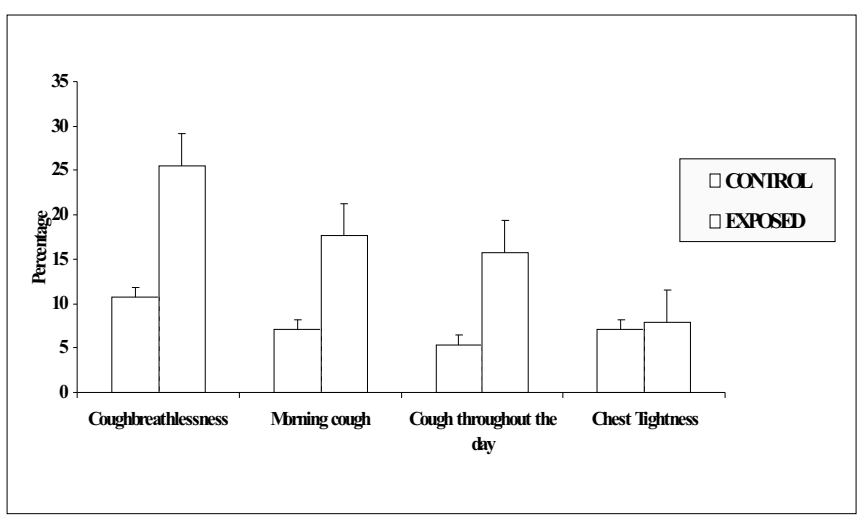

Figure 3: Distribution of other respiratory symptoms of both control and exposed male beedi workers 
Table 3: Lung volumes and flow rates of exposed and control male beedi workers according to smoking habit (mean \pm SD)

\begin{tabular}{|c|c|c|c|c|c|c|}
\hline Parameters & Smoking habits & Beedi workers & Smoking habits & Control subjects & $\begin{array}{l}\text { Percentage } \\
\text { changes }\end{array}$ & $\boldsymbol{P}$ values \\
\hline SVC (I) & $\begin{array}{l}\text { Non-smoker } n=16 \\
\text { smoker } n=35\end{array}$ & $\begin{array}{l}3.94 \pm 0.51 \\
3.82 \pm 0.77\end{array}$ & $\begin{array}{c}\text { Non-smoker } n=29 \\
\text { smoker } n=27\end{array}$ & $\begin{array}{l}4.02 \pm 0.69 \\
3.89 \pm 0.88\end{array}$ & $\begin{array}{l}-1.99 \\
-1.80\end{array}$ & $\begin{array}{l}\text { NS } \\
\text { NS }\end{array}$ \\
\hline FVC (I) & $\begin{array}{c}\text { Non-smoker } n=16 \\
\text { smoker } n=35\end{array}$ & $\begin{array}{l}4.11 \pm 0.41 \\
3.62 \pm 0.97\end{array}$ & $\begin{array}{c}\text { Non-smoker } n=29 \\
\text { smoker } n=27\end{array}$ & $\begin{array}{l}4.00 \pm 0.68 \\
3.91 \pm 0.65\end{array}$ & $\begin{array}{l}+2.75 \\
-7.42\end{array}$ & $\begin{array}{l}\text { NS } \\
\text { NS }\end{array}$ \\
\hline FEV 1 (I) & $\begin{array}{c}\text { Non-smoker } n=16 \\
\text { smoker } n=35\end{array}$ & $\begin{array}{l}3.69 \pm 0.48 \\
3.34 \pm 0.95\end{array}$ & $\begin{array}{c}\text { Non-smoker } n=29 \\
\text { smoker } n=27\end{array}$ & $\begin{array}{l}3.61 \pm 0.63 \\
3.52 \pm 0.63\end{array}$ & $\begin{array}{l}+2.22 \\
-5.11\end{array}$ & $\begin{array}{l}\text { NS } \\
\text { NS }\end{array}$ \\
\hline $\mathrm{FEV}_{1 \%}$ & $\begin{array}{c}\text { Non-smoker } n=16 \\
\text { smoker } n=35\end{array}$ & $\begin{array}{c}93.00 \pm 6.99 \\
84.70 \pm 10.90\end{array}$ & $\begin{array}{c}\text { Non-smoker } n=29 \\
\text { smoker } n=27\end{array}$ & $\begin{array}{l}90.07 \pm 4.80 \\
89.48 \pm 5.50\end{array}$ & $\begin{array}{l}-3.15 \\
-5.34\end{array}$ & $\begin{array}{l}\text { NS } \\
<0.05\end{array}$ \\
\hline $\mathrm{FEF}_{.2-1.21 \mathrm{ml}}(\mathrm{l} / \mathrm{sec})$ & $\begin{array}{c}\text { Non-smoker } n=16 \\
\text { smoker } n=35\end{array}$ & $\begin{array}{l}7.89 \pm 1.51 \\
6.64 \pm 2.40\end{array}$ & $\begin{array}{c}\text { Non-smoker } n=29 \\
\text { smoker } n=27\end{array}$ & $\begin{array}{l}7.38 \pm 1.83 \\
7.12 \pm 1.58\end{array}$ & $\begin{array}{l}-6.91 \\
-6.74\end{array}$ & $\begin{array}{l}\text { NS } \\
\text { NS }\end{array}$ \\
\hline $\mathrm{FEF}_{25-75 \%}(\mathrm{I} / \mathrm{sec})$ & $\begin{array}{c}\text { Non-smoker } n=16 \\
\text { smoker } n=35\end{array}$ & $\begin{array}{l}4.49 \pm 1.66 \\
4.16 \pm 1.88\end{array}$ & $\begin{array}{c}\text { Non-smoker } n=29 \\
\text { smoker } n=27\end{array}$ & $\begin{array}{l}4.75 \pm 1.45 \\
4.56 \pm 1.13\end{array}$ & $\begin{array}{l}-5.47 \\
-8.77\end{array}$ & $\begin{array}{l}\text { NS } \\
\text { NS }\end{array}$ \\
\hline $\mathrm{FEF}_{75-85 \%}(1 / \mathrm{sec})$ & $\begin{array}{c}\text { Non-smoker } n=16 \\
\text { smoker } n=35\end{array}$ & $\begin{array}{l}2.38 \pm 1.85 \\
1.87 \pm 1.45\end{array}$ & $\begin{array}{c}\text { Non-smoker } n=29 \\
\text { smoker } n=27\end{array}$ & $\begin{array}{l}1.99 \pm 0.77 \\
1.71 \pm 0.56\end{array}$ & $\begin{array}{c}+19.96 \\
+9.31\end{array}$ & $\begin{array}{l}\text { NS } \\
\text { NS }\end{array}$ \\
\hline PEFR (Liter/sec) & $\begin{array}{c}\text { Non-smoker } n=16 \\
\text { smoker } n=35\end{array}$ & $\begin{array}{c}490.31 \pm 70.49 \\
460.14 \pm 102.88\end{array}$ & $\begin{array}{c}\text { Non-smoker } n=29 \\
\text { smoker } n=27\end{array}$ & $\begin{array}{c}509.83 \pm 9.19 \\
505.74 \pm 58.50\end{array}$ & $\begin{array}{l}-3.05 \\
-9.02\end{array}$ & $\begin{array}{l}\mathrm{NS} \\
<0.05\end{array}$ \\
\hline
\end{tabular}

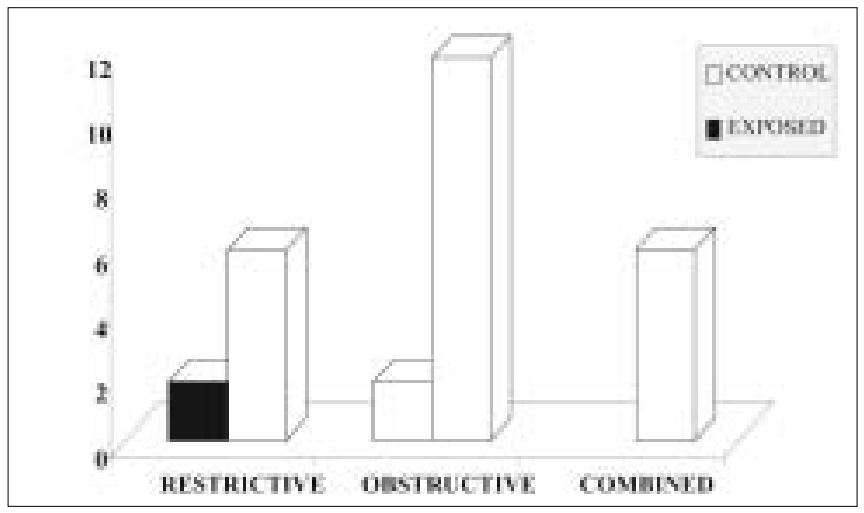

Figure 4: Comparison of respiratory impairments of both control \& exposed male beedi workers

are $1.79 \%$ restrictive and $1.79 \%$ obstructive. No combined type of impairments was found in control subjects.

\section{DISCUSSION}

Tobacco dust contains various immunological active as well as toxic substances. It has been established that occupational chronic exposure to the dust of tobacco leaves is associated with significant increases in the occurrence of mild obstructive ventilatory disturbances. ${ }^{[9]}$ Tobacco dust mainly contains nitrosamines, which are readily absorbed by the body tissues like skin, respiratory epithelium and mucus membrane of mouth, nose and intestines. Exposure to tobacco dust is known to affect the respiratory tract in humans. ${ }^{[10]}$ This study was designed to investigate the beedi tobacco dust exposure and its effect on pulmonary function status. The present study shows an association between pulmonary function impairments and exposure to beedi tobacco dust.

In India, workers engaged in the processing of tobacco for the manufacture of beedis (the indigenous substitute for cigarettes) are chronically exposed to tobacco flakes and dust via the cutaneous and nasopharyngeal routes. ${ }^{[1]}$ Earlier studies reported that in India over 3 million workers employed in the beedi industry receive massive chronic exposure to unburnt tobacco, mainly by the cutaneous and nasopharyngeal routes, which may develop pulmonary function impairments among the workers exposed to that environment. ${ }^{[12]}$

In the present study, the age, height, weight, body surface area and body mass index were comparable among beedi workers and the control subjects. The ventilatory capacity in tobacco workers showed a reduction in $\mathrm{FEV}_{1^{\prime}}, \mathrm{FEF}_{50}$ and $\mathrm{FEF}_{25}$ in relation to their predicted values. ${ }^{[13]}$ In the present study, reduction of mean values of lung volumes, i.e., SVC, FVC, FEV and $\mathrm{FEV}_{1 \%}$, are noted in exposed workers compared to control subjects. Only the difference of PEFR between control and exposed workers was shown to be significant $(P<0.05)$.

The mean $\mathrm{FEV}_{1}$ as percentage of the FVC $\left(\mathrm{FEV}_{1 \%}\right)$ of the tobacco farm workers (TFW) was different from that of the control with duration of service. ${ }^{[14]}$ This result in the TFWs may be attributed to the long-term exposure due to carrying and stacking of tobacco leaves. Present study results showed that as the duration of exposure increased, there was a decrement of lung volumes and flow rates in exposed beedi workers. The values of some lung function tests for exposed nonsmoker workers were significantly lower than the control nonsmoker workers. ${ }^{[15]}$ This could be attributed to the effect of occupational exposure on the respiratory system. In the present study, a significant difference was noted in $\mathrm{FEV}_{1 \%}$ and PEFR $(P<0.05)$ in the exposed smoker workers compared to the control workers. Lung functions were lower in exposed nonsmoker workers compared to control nonsmoker workers.

A low prevalence of chronic respiratory symptoms was found in control workers and the prevalence of cough with breathlessness, morning cough were higher among workers exposed to tobacco dust than the control. ${ }^{[16]}$ In the present 
study, findings of the symptomatic changes, i.e., cough, cough throughout the day, chest tightness were noticed to be higher in exposed workers than the control subjects, which is highly corroborated by the study results of Kjaergaard. ${ }^{[17]}$

Mostly the small airways are affected much by the exposure to tobacco dust. ${ }^{[18]}$ The spirometric assessment showed a tendency of restriction- and obstruction-type changes, especially in small airways of tobacco industry workers. ${ }^{[19]}$ In the present study, the respiratory impairments as a whole were found higher among the exposed subjects (23.53\%), in which $5.88 \%$ were restrictive, $11.76 \%$ were obstructive and $5.8 \%$ were of the 'combined restrictive and obstructive' type. These types of pulmonary function impairments might be due to their exposure to tobacco dust during beedi-making.

\section{ACKNOWLEDGMENTS}

The authors are grateful to the Director, National Institute of Occupational Health (NIOH), Ahmedabad ${ }_{i}$ and the Officer in Charge, Regional Occupational Health Centre (E), Kolkata, for granting permission to carry out the study. The authors gratefully acknowledge the cooperation received from Dr. R. K. Ganguly, Head, Department of Postgraduate Physiology, University of Kalyani, West Bengal ${ }_{i}$ and Mr. Barkat Ali, M.Sc. student of Physiology, in carrying out this study. The authors thankfully acknowledge the cooperation rendered by the male beedi workers and non-exposed male subjects; their kind cooperation in this investigation is highly appreciated from the core of our heart.

\section{REFERENCES}

1. Czeslawa S, Barbara M, Jacek D, Ewa KT, Janusz M, Helen F, et al. Effect of exposure to grain dust in polish farmers: Work related to symptoms and immunological response to microbial antigen associated with dust. Ann Argic Environ Med 1998;5:147-53.

2. Mengesha YA, Bekele A. Relative chronic effects of occupational dust on respiratory indices and health of workers in three Ethiopian factories. Am J Ind Med 1998;34:373-80.

3. Imbus HR. Clinical aspects of occupational medicine. In: Carl, Zonz, O. Bruce, Dickerson, Edward, Horvath P, editors. Occupational medicine. $3^{\text {rd }}$ ed. Mosby Press: London; 1994. p. 3.

4. Ruppel GL. Pulmonary function testing. Trends and techniques. North Am Resp Care Clin 1997. p. 155-81.

5. Chattopadhayay BP, Saiyed HN, Alam J, Roy SK, Thakur S, Dasgupta TK. Injury into occurrence of Byssinosis in Jute mill workers. J Occup Hlth 1999;41:225-31.

6. Chattopadhayay BP, Alam J. Spirometric function of ventilatory function of non-smokers and different graded of smokers of Calcutta. Indian J Environ Protec 1996;14:274-9.

7. Du Bois D, Du Bois EF. A formula to estimate the approximate surface area if height and weight be known 1916. Nutrition 1989;5:303-11.

8. Chatterjee S, Saha D, Chattopadhayay BP. Pulmonary function studies in healthy non-smoking men of Calcutta. Ann Hum Biol 1988;15:36574.

9. Ignacak A, Guizik TJ, Gorski L, Czerniawska-Mysik G, Adamek-Guzik T. Influence of tobacco dust on the respiratory system and selected immunological parameters. Przegl lek 2002;10:789-92.

10. Umadevi B, Swarna M, Padmavathi P, Jyothi A, Reddy PP. Cytogenetic effect in workers occupationally exposed to tobacco dust. Mutat Res 2003;535:147-54.

11. Mahimkar MB, Bhisey RA. Occupational exposure to Bidi tobacco increases chromosomal aberrations in tobacco processors. Mutat Res 1995;2:139-44.

12. Bagwe AN, Bhisey RA. Occupational exposure to tobacco and resultant genotoxicity in Bidi industry workers. Mutat Res 1993;2:103-9.

13. Mustajbegovic J, Zuskin E, Schachter EN, Kern J, Luburic-Milas M, Pucarin J. Respiratory findings in tobacco workers. Chest 2003;5:1740-8.

14. Osim EE, Musabayane CT, Mujamda J. Lung function of Zimbabwean farm workers exposed to flue caring and stacking of tobacco leaves. S Afr Med J 1998;88:1127-31.

15. Popovic V, Arandelovic M, Javanovic J, Momcilovic O, Veselic E, Dordevic D, et al. The effect of occupational noxae in the tobacco industry on pulmonary function in exposed workers. Arh Hig Rada Toksikal 1992;1:37-45.

16. Valic F, Beritic D, Butkovic D. Respiratory response to tobacco dust exposure. Am Rev Respir Dis 1976;6:751-5.

17. Kjaergaard SK, Pederson OF, Frydenberg M, Schanheyder H, Anderson $\mathrm{P}$, Bande GJ. Respiratory disease and lung function in a tobacco industry. Arch Environ Health 1989;3:164-70.

18. Mukhtar MS, Rao GM, Gamra NS, Afan AM, Zendah MI. Respiratory effects of occupational exposure to tobacco dust. Respiration 1991;56:271-6.

19. Huuskonen MS, Husman K, Janvisalo J, Karhonen O, Kotimaa M, Kuusela T, et al. Extrinsic allergic alveolitis in the tobacco industry. Br J Ind Med 1984;1:77-83.

Source of Support: Nil, Conflict of Interest: None declared. 